\title{
Effect of Varying Duration of Ocular Compression on Raised Intraocular Pressure following Fractionated Peribulbar Anaesthesia for Cataract Surgery
}

\author{
Jaichandran Venkatakrishnan, ${ }^{1}$ Lingam Vijaya, ${ }^{2}$ Ronnie J George, ${ }^{2}$ Thennarasu \\ Maruthamuthu ${ }^{3}$ \\ ${ }^{1}$ Department of Anesthesiology, ${ }^{2}$ Department of Glaucoma, and ${ }^{3}$ Department of Biostatistics, \\ Medical Research Foundation, Sankara Nethralaya, Chennai, India
}

\begin{abstract}
Aim: To evaluate the effect of fractionated peribulbar anaesthesia and varying digital ocular compression time on intraocular pressure.

Methods: Forty non-glaucomatous patients aged 40 years and older planned for cataract surgery were randomly divided into 2 groups based on the duration for which the globe was compressed digitally following each injection. Patients with a history of glaucoma or those who had had previous ocular surgery were excluded. Group 1 underwent 1 minute of compression and group 2 underwent 2 minutes of compression. Local anaesthetic ( $2 \%$ lidocaine $5 \mathrm{~mL}, 0.5 \%$ bupivacaine $5 \mathrm{~mL}$, and hyaluronidase $25 \mathrm{IU} / \mathrm{mL}$ ) was injected into the inferotemporal and superomedial quadrants. Intraocular pressure was measured (3 readings with $<5 \%$ SD) before peribulbar block, after inferotemporal injection, following digital compression, after superomedial injection, following digital compression again, and at 1-minute intervals without compression until the globe attained normotension.

Results: The mean (SD) intraocular pressure in group 1 was significantly elevated compared with the baseline mean intraocular pressure of $19.21 \mathrm{~mm} \mathrm{Hg}(S D, 2.82 \mathrm{~mm} \mathrm{Hg})$ throughout the procedure $(p<0.0001)$. In group 2, the mean intraocular pressure was not significantly elevated from the baseline mean intraocular pressure of $19.13 \mathrm{~mm} \mathrm{Hg}(S D, 3.27 \mathrm{~mm} \mathrm{Hg}$ ) following compression after each injection.

Conclusions: Intraocular pressure rises significantly following each $5 \mathrm{~mL}$ of local anaesthetic injected into the peribulbar space at both the inferotemporal and superomedial sites. Digital ocular compression given for 2 minutes after each injection makes the globe normotensive.
\end{abstract}

Key words: Anesthesia, local, Cataract extraction, Glaucoma, Intraocular pressure

Asian J Ophthalmol. 2011;12:197-200.

\section{Introduction}

Peribulbar anaesthesia is a commonly used regional technique for performing cataract surgery under local anaesthesia. ${ }^{1}$ In this technique, the local anaesthetic is injected outside the muscle cone. This results in a larger volume of the drug being required, as it has to diffuse through the orbital connective tissue septa and the muscle cone to block the motor and sensory nerves of the eye. ${ }^{2}$ Larger drug volumes raise the intraorbital and intraocular pressure (IOP) to a greater extent than the retrobulbar technique, for which relatively less volume of drug is required ${ }^{3,4} \mathrm{~A}$ soft eye is

Correspondence: Dr Jaichandran Venkatakrishnan, 41/18,

Nungambakkam, College Road, Chennai 600 006, Tamil Nadu, India. Tel: (91 44) 2827 1616;

E-mail: jaichand1971@yahoo.com preferred during cataract surgery as, in this state, the vitreous will remain concave after lens extraction and minimize intraoperative complications. ${ }^{5}$ To aid uniform diffusion of the drug and to make the globe softer, some form of ocular compression is necessary following each injection in fractionated peribulbar anaesthesia.

Although medial injections are considered to be safe, perforation of the globe has been reported to occur in patients for whom the second medial injection, placed medial to the caruncle, was given immediately following the first injection into the inferotemporal compartment. ${ }^{6}$ Injecting $5 \mathrm{~mL}$ of local anaesthetic into the inferotemporal compartment causes the globe to be displaced medially and superiorly. Before inserting a needle into the superomedial compartment, the globe should be returned to the anatomical position by compression. Effective compression 
of the globe reduces the risk of perforation and creates sufficient space for supplemental injections to be given. ${ }^{6}$ Review of the literature shows that, in fractionated peribulbar anaesthesia, the minimum effective duration of digital compression of the globe after each injection to maintain the baseline IOP throughout is not clearly defined. With this background, this study was designed to evaluate the effect on IOP following each injection and of varying digital ocular compression times of 1 and 2 minutes in fractionated peribulbar anaesthesia.

\section{Methods}

\section{Patients}

Forty patients aged 40 years and older planned for cataract surgery (phacoemulsification) under local anaesthesia were enrolled. The patients were randomly divided into 2 groups based on the duration for which digital ocular compression was given: group 1 for 1 minute and group 2 for 2 minutes. Patients with a history of glaucoma or ocular hypertension, or who had previously undergone any ocular or orbital surgery were excluded. Institutional ethics committee approval and written informed consent was obtained.

\section{Design}

All patients received $2 \%$ lignocaine hydrochloride $5 \mathrm{~mL}$ (Xylocaine $2 \%$; AstraZeneca, Bangalore, India), $0.2 \%$ bupivacaine $5 \mathrm{~mL}$ (Sensorcaine $0.5 \%$; AstraZeneca, Bangalore, India), and hyaluronidase $25 \mathrm{IU} / \mathrm{mL}$ injection (Hynidase; Shreya Life Sciences, Aurangabad, India) for the peribulbar block. The block was administered using a $23 \mathrm{G}$, 1-in blunt steel needle. Routine monitoring for all patients included electrocardiogram, non-invasive arterial pressure monitoring, and pulse oximetry. Both the block and digital compression were performed by a single individual throughout the study.

Before administering the peribulbar block, the IOP was measured with a Tono-pen $\circledast \mathrm{XL}$ (3 readings with $<5 \% \mathrm{SD}$, Medtronic Solan, Jacksonville, USA) by a blinded observer. For all patients, the needle was first inserted through the eyelid at a point between the lateral third and medial two-thirds of the lower orbital margin, with the bevel facing the globe. The needle was then advanced in a superomedial direction (parallel to the plane of the orbital floor) for a distance of approximately $25 \mathrm{~mm}$ to the equator of the globe, where the anaesthetic solution was injected outside the muscle cone at a rate of $5 \mathrm{~mL} / 10$ seconds. ${ }^{2}$ Immediately after this inferior block, the IOP was measured.

The globe was compressed gently with the middle 3 fingers placed over a sterile gauze pad on the upper eyelid with the middle finger pressing directly down on the eyeball. Every 30 seconds, digital pressure was released for 5 seconds to allow for the vascular pulsations to occur. Following this compression, the IOP was measured.

The second injection was given in the superomedial compartment. The needle was introduced through the upper lid at about $2 \mathrm{~mm}$ medial and inferior to the supraorbital notch. The needle was then advanced in a sagittal plane under the roof of the orbit for a maximal depth of $25 \mathrm{~mm}$, where the remaining $5 \mathrm{~mL}$ of local anaesthetic was injected at a similar rate as for the inferior injection. ${ }^{2}$ Injection of the local anaesthetic was stopped when there was either firmness in the globe or any resistance to further depressing the plunger of the syringe was felt. The IOP was measured again after the second injection was given.

Digital compression of the globe was performed as described above, following which the IOP was measured. Then, the IOP was measured at 1-minute intervals until the globe attained normotension ( $<22 \mathrm{~mm} \mathrm{Hg}$ ) without compression.

\section{Statistical Analysis}

The sample size ( $\mathrm{n}=20$ in each group) was calculated to detect a significant difference in IOP between the groups following compression after inferolateral injection, aiming for a power of $80 \%$ and $\alpha$ error of 0.05 , after performing a pilot study of 20 patients. All the results are expressed as mean (SD). The results were considered significant if $\mathrm{p}$ was $<0.05$. Independent $t$ test was used for comparing the mean IOP between the groups and paired $t$ test was used to compare the significant difference in the mean baseline IOP and mean IOP obtained after injection and compression.

\section{Results}

The mean age, sex, and weight of the patients enrolled for the study were statistically similar between the groups (Table 1). The mean IOP recorded in both groups before and after peribulbar injections and ocular compression are shown in Table 2. In both groups, the mean IOP was significantly elevated from baseline following injection of local anaesthetic $5 \mathrm{~mL}$ into either the inferotemporal or superomedial quadrant $(p<0.0001)$. In group 1 , even after digital compression following inferolateral and superomedial

Table 1. Patients' characteristics by group.

\begin{tabular}{|lcc|}
\hline Characteristic & $\begin{array}{c}\text { Group } \mathbf{1}^{*}(\mathbf{n}=\mathbf{2 0}) \\
\text { Mean (SD) }\end{array}$ & $\begin{array}{c}\text { Group } \mathbf{2}^{*}(\mathbf{n}=\mathbf{2 0}) \\
\text { Mean }(\mathbf{S D})\end{array}$ \\
\hline Age (years) & $60.85(7.43)$ & $62.05(9.11)$ \\
Sex & & \\
$\quad$ Male & 17 & 19 \\
Female & 23 & 21 \\
Weight (kg) & $61(8.99)$ & $60.35(9.48)$ \\
\hline
\end{tabular}

* None of the differences were significant; $p>0.05$. 
Table 2. Mean intraocular pressure $(\mathrm{mm} \mathrm{Hg})$ before and after peribulbar injection and ocular digital compression by group.

\begin{tabular}{|lcc|}
\hline Variable & $\begin{array}{c}\text { Group 1 }(\mathbf{n}=\mathbf{2 0}) \\
\text { Mean (SD) }\end{array}$ & $\begin{array}{c}\text { Group 2 (n= 20) } \\
\text { Mean (SD) }\end{array}$ \\
\hline Baseline IOP & $19.22(2.82)$ & $19.13(3.27)$ \\
IOP after inferolateral injection & $25.17(3.46)^{\star}$ & $24.08(3.29)^{\star}$ \\
IOP after digital compression & $23.68(4.01)^{\star}$ & $18.15(4.28)^{\dagger}$ \\
IOP after superomedial injection & $42.82(15.13)^{\star}$ & $30.37(7.02)^{\star}$ \\
IOP after digital compression & $28.92(6.53)^{\star}$ & $19.37(3.50)^{\dagger}$ \\
95\% confidence interval & $26.05-31.78$ & $17.83-20.90$ \\
Time taken to reach baseline IOP (minutes) & $3.70(2.22)$ & $0.10(0.30)$ \\
\hline
\end{tabular}

${ }^{*} p<0.0001$ compared with baseline IOP.

${ }^{t} p>0.05$ compared with baseline IOP.

Abbreviation: $\mathrm{IOP}=$ Intraocular pressure.

Figure 1. Mean intraocular pressure $(\mathrm{mm} \mathrm{Hg})$ at baseline and after inferolateral and superomedial injection and digital compression.

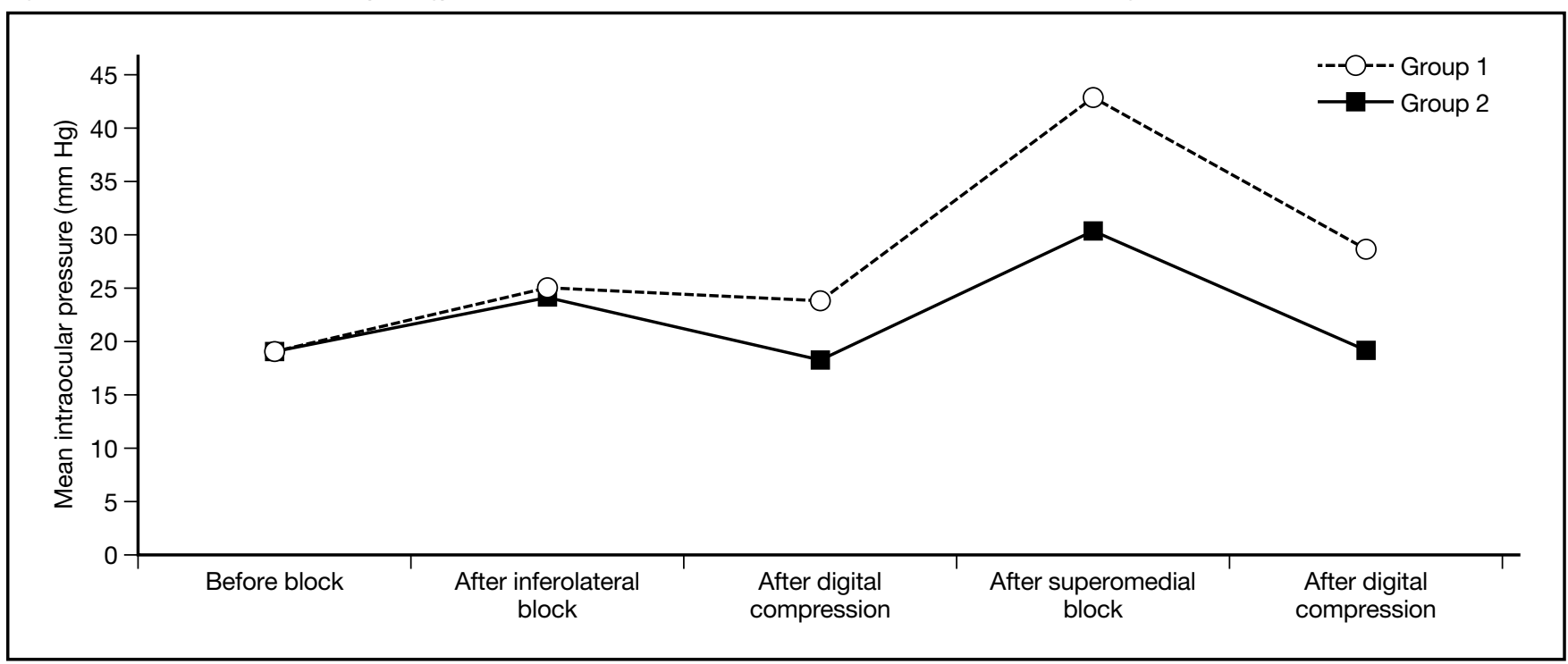

injection, the IOP was significantly increased to $23.68 \mathrm{~mm} \mathrm{Hg}$ (SD, $4.01 \mathrm{~mm} \mathrm{Hg}$ ) and $28.92 \mathrm{~mm} \mathrm{Hg}(\mathrm{SD}, 6.53 \mathrm{~mm} \mathrm{Hg})$, respectively, from the baseline IOP of $19.22 \mathrm{~mm} \mathrm{Hg}(\mathrm{SD}, 2.82 \mathrm{~mm} \mathrm{Hg})$ $[p<0.0001]$. The mean time interval required for the globe to attain normotension was 3.7 minutes. In group 2, digital compression following inferolateral injection reduced the IOP to a mean of $18.10 \mathrm{~mm} \mathrm{Hg}$ (SD, $4.28 \mathrm{~mm} \mathrm{Hg}$ ) compared with the baseline IOP of $19.13 \mathrm{~mm} \mathrm{Hg}$ (SD,3.27 mm Hg) [p = 0.122], and the globe attained normotension (19.37 mm Hg [SD, $3.50 \mathrm{~mm} \mathrm{Hg}$ ) immediately following compression after superomedial injection (Figure 1).

\section{Discussion}

For intraocular surgeries such as intracapsular/extracapsular cataract extraction with or without intraocular lens implantation and trabeculectomy, it is important to prevent any iatrogenic pressure rise before a surgical incision is made. As soon as the sclera is surgically incised, the IOP equates atmospheric pressure. If the pressure is high at the time of incision, the intraocular contents, namely the iris, lens, vitreous, and retina, may be expelled through the wound. ${ }^{7}$ Sudden decompression of a hypertensive eye may also increase the likelihood of rupture of the sclerotic short posterior ciliary artery in the choroid, thus producing an expulsive haemorrhage in the eye. ${ }^{8}$ Therefore, it is important to ensure that the IOP is maintained at a low-normal level before a surgical incision is made.

In this study, injection of $5 \mathrm{~mL}$ of local anaesthetic into the inferolateral quadrant resulted in a mean rise of 5 to $6 \mathrm{~mm} \mathrm{Hg}$ from the baseline IOP in both groups. Digital compression of the globe following peribulbar injection results in a uniform distribution of the local anaesthetic across the globe and helps to decrease the IOP. The mean decrease in IOP following digital compression after inferolateral block was $1.49 \mathrm{~mm} \mathrm{Hg}$ in group 1 and $5.93 \mathrm{~mm} \mathrm{Hg}$ in group 2. A mean decrease in IOP of $5.4 \mathrm{~mm} \mathrm{Hg}$ was recorded in a previous study, in which digital massage was given for 3 to 5 minutes. $^{5}$

In both groups, the mean change in IOP following inferolateral injection and compression was different from than following superomedial injection and compression. Following superomedial injection, 
a mean increase of $19.14 \mathrm{~mm} \mathrm{Hg}$ in group 1 and $12.22 \mathrm{~mm} \mathrm{Hg}$ in group 2 was recorded. In group 1, before administering superomedial block, the globe was already in a hypertensive state with a mean IOP of $23.68 \mathrm{~mm} \mathrm{Hg}$ (SD, $4.01 \mathrm{~mm} \mathrm{Hg}$ ). This resulted in a much greater increase in IOP following superomedial block in group 1 compared with group 2, in whom the globe was in a normotensive state before administration of superomedial injection, with a mean IOP of $18.1 \mathrm{~mm} \mathrm{Hg}$ (SD, $4.28 \mathrm{~mm} \mathrm{Hg}$ ). These findings suggest that, in eyes with a high initial resting IOP, steeper increases in pressure can occur following peribulbar injections than in normotensive eyes. This finding is corroborated by 0'Donoghue et al's report that patients with glaucoma experienced higher and more persistent increases in IOP than those without glaucoma. ${ }^{9}$

Unlike the mean decrease in IOP that occurred following compression after inferolateral injection, mean decreases of $13.9 \mathrm{~mm} \mathrm{Hg}$ in group 1 and $11.0 \mathrm{~mm} \mathrm{Hg}$ in group 2 were recorded following compression after superolateral injection. Despite this large decrease in mean IOP in group 1, the mean IOP was still found to be significantly raised at $28.92 \mathrm{~mm} \mathrm{Hg}(\mathrm{SD}, 6.53 \mathrm{~mm} \mathrm{Hg})$, and it took an approximate mean time interval of 4 minutes to attain the baseline IOP without any compression of the globe.

Peribulbar block with only $5 \mathrm{~mL}$ of local anaesthetic solution would be more likely to produce either inadequate analgesia or akinesia in the eye, and many patients would require supplementation. ${ }^{10}$ Therefore, to obtain an effective block and have uniformity in administering the block to all patients, the study was designed in such a way that following injection of $5 \mathrm{~mL}$ of local anaesthetic solution, a second injection would be given until either any firmness in the globe or resistance to further depressing the plunger of the syringe was felt.

Previous studies have documented that, for peribulbar anaesthesia, the longer the duration the globe was compressed the better was the reduction in IOP.11 In this study, the focus was mainly on the minimum time for which the globe has to be compressed digitally in non-glaucomatous eyes to maintain normotension following peribulbar injection. Further studies should be done in glaucomatous eyes to evaluate the effect on IOP following fractionated peribulbar injection and to know whether the globe has to be compressed digitally for 2 minutes or more to maintain normotension.

For patients with non-glaucomatous eyes undergoing cataract surgery under fractionated peribulbar block, to maintain the baseline IOP between each injection and to provide sufficient peribulbar space to accommodate the anaesthetic fluid to be injected subsequently, the globe has to be compressed digitally for a minimum time of 2 minutes.

\section{References}

1. Eke T, Thompson JR. The national survey of local anaesthesia for ocular surgery. Survey methodology and current practice. Eye. 1999;13:189-95.

2. Wong $\mathrm{DH}$. Regional anaesthesia for intraocular surgery. Can $J$ Anaesth. 1993;4:635-57.

3. Lanini PG, Simona FS. Change in intraocular pressure after peribulbar and retrobulbar injection: practical sequelae. Klin Monatsbl Augenheilkd. 1998;212:283-5.

4. Sanford DK, Minoso y de Cal OE, Belyea DA. Response of intraocular pressure to retrobulbar and peribulbar anaesthesia. Ophthalmic Surg Lasers. 1998;29:815-7.

5. Sud RN, Loomba R. Achievement of surgically soft and safe eyes - a comparative study. Indian J Ophthalmol. 1991;39:12-4.

6. Ball JJ, Woon WH, Smith S. Globe perforation by the second peribulbar injection. Eye. 2002:16:663-5.

7. Duncalf D. Anaesthesia and intraocular pressure. Bull N Y Acad Med. 1975;51:374-9.

8. Cunningham AJ, Barry P. Intraocular pressure - physiology and implications for anaesthetic management. Can J Anaesth 1986;33:195-208.

9. O'Donoghue E, Batterbury M, Lavy T. Effect on intraocular pressure of local anaesthesia in eyes undergoing intraocular surgery. $\mathrm{Br} J$ Ophthalmol. 1994;78:605-7.

10. Kumar CN, Dodds C. Ophthalmic regional block. Ann Acad Med Singapore. 2006;35:158-67.

11. Ubah J, Ajayi BJ, Bekibele CO. Comparison of fixed weight and digital massage techniques for intraocular pressure reduction after peribulbar anaesthesia. Nigerian J Ophthalmol. 2004;12:60-4. 